\title{
Intestinal Obstruction Due to Retained, Eroding Surgical Sponge: A Case Report
}

\author{
Fatma K. Al Thubaity \\ Department of Surgery, Faculty of Medicine, \\ King Abdulaziz University, Jeddah, Saudi Arabia
}

\begin{abstract}
Gossypiboma is not an uncommon surgical complication but it is rarely reported mainly due to medico-legal problems. A case of a surgical sponge left in the peritoneal cavity at caesarean section eroded into the bowel and caused intestinal obstruction one year later is presented. She was treated with small bowel resection. Small bowel wall opened by enterotomy and sponge removed. A report of a correct sponge count in the operating room does not exclude the possibility of a retained surgical sponge. Certainly it is the responsibility of the surgeon to make sure that he did not leave any sponge behind. This issue will be discussed in this paper. The English literature was reviewed.
\end{abstract}

Keywords: Intestinal obstruction, Gossypiboma, Transmural migration.

\section{Introduction}

The term "gossypiboma" denotes a cotton foreign body that is retained inside following surgery. It has been reported to occur following surgical procedures such as abdominal, thoracic, cardiovascular, orthopaedic, and even neurosurgical operations. It has been reported as 1 in 1,000 to 1,500 for abdominal operations. It can create a medico-legal problem especially for surgeons. Gossypiboma is one of the rare causes of an intestinal obstruction. It is the dread of every surgeon. This is the first case reported in our hospital of small bowel obstruction caused by transmural migration of laparotomy sponge without opening of the intestinal wall.

Correspondence \& reprint requests to: Dr. Fatma K. Al-Thubaity

P.O. Box 80215, Jeddah 21589 Saudi Arabia

Accepted for publication: 25 June 2005. Received: 10 May 2005. 
A 27-year-old Somali female patient presented with slowly growing abdominal pain and vomiting for one year. It was associated with loss of weight. Absolute constipation for one week and abdominal distension for one day duration. She had cesarean section one-year ago which was done in a hospital other than our hospital.

On examination her temperature is $37.4^{\circ} \mathrm{C}$, blood pressure $140 / 86 \mathrm{mmHg}$. Abdominal examination revealed distended abdomen with scar of caesarean section, diffuse tenderness and reducible paraumbilical hernia. Investigation showed leukocytosis, Kidney, ureter, and bladder (KUB) showed distended small bowel with metallic marker (Fig. 1) and abdomen computerized tomography (CT) scan showed distended, abnormally small bowel with hyperdense lesion inside it, mottled appearance suggestive of gangrene (Fig. 2).

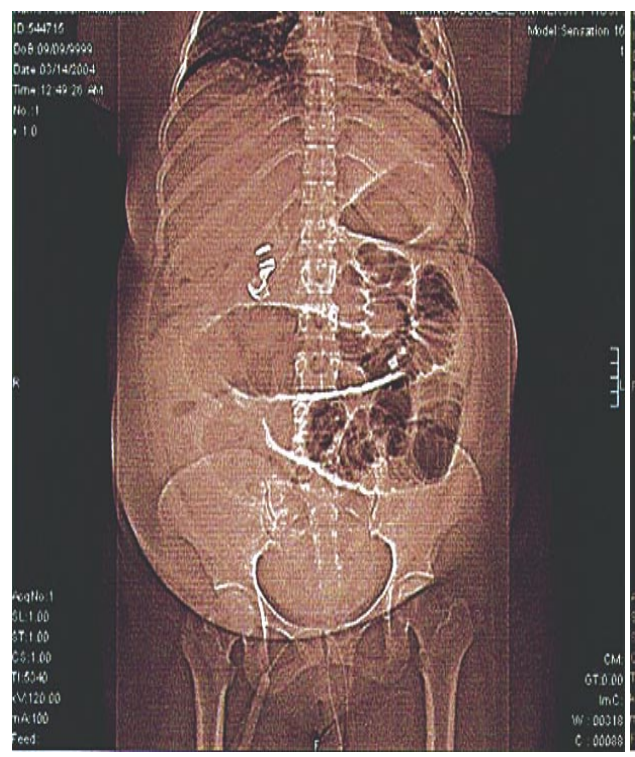

Fig. 1. KUB showing a metallic marker with distended small bowel.

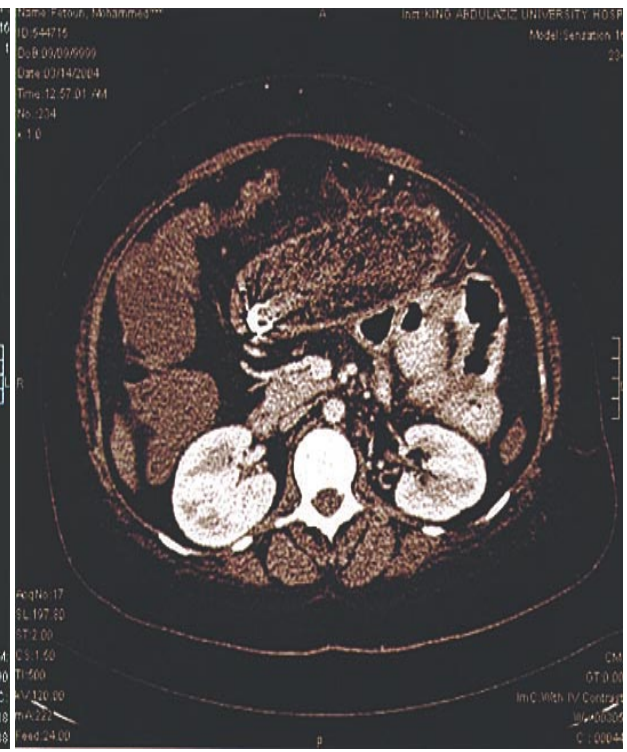

Fig. 2. C.T. scan of abdomen showing a distended abnormal small bowel loop with hyperdense lesion inside it.

Laparotomy was carried out and an ileal loop measuring $9 \mathrm{~cm}$ was found to be gangrenous, distended by an inside large and hardened mass with intestinal loops (Fig. 3) and omentum density adherent. Small bowel resected (Fig. 4) and primary anastomosis was performed. The length of the resected specimen is $70 \mathrm{~cm}$. Surgical specimen was opened (Fig. 5) and intraluminal surgical sponge removed (Fig. 6). No opening of intestinal wall. Histopathology of gangrenous part shows loss of surface epithelium and acute inflammatory cell infiltrate extending to the serosa. 


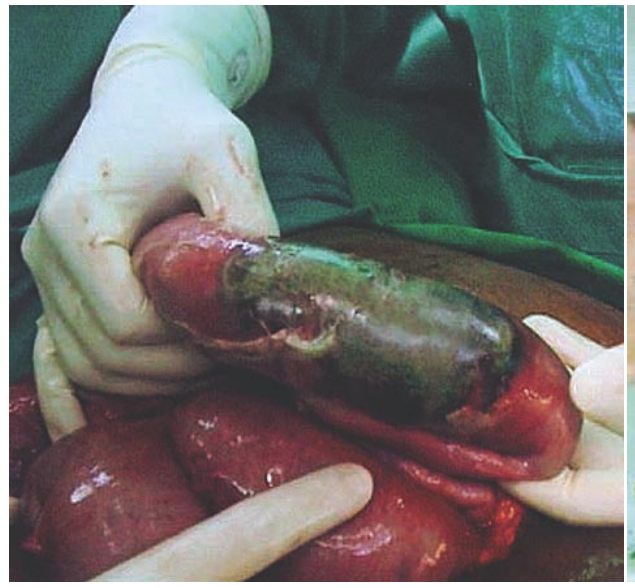

Fig. 3. Gangrenous ileal loop with hardened mass inside it.

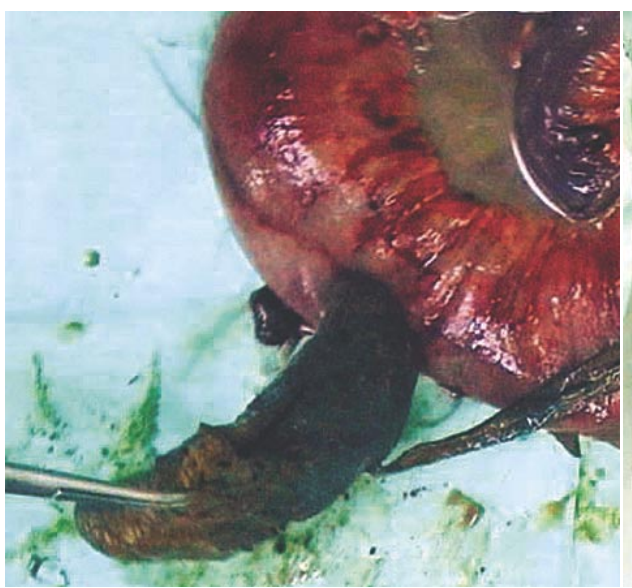

Fig. 5. Opening of the intestinal wall.

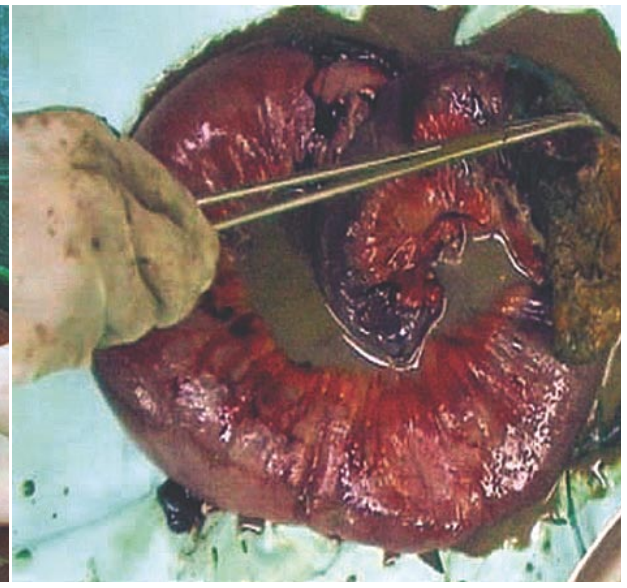

Fig. 4. Resected small bowel.

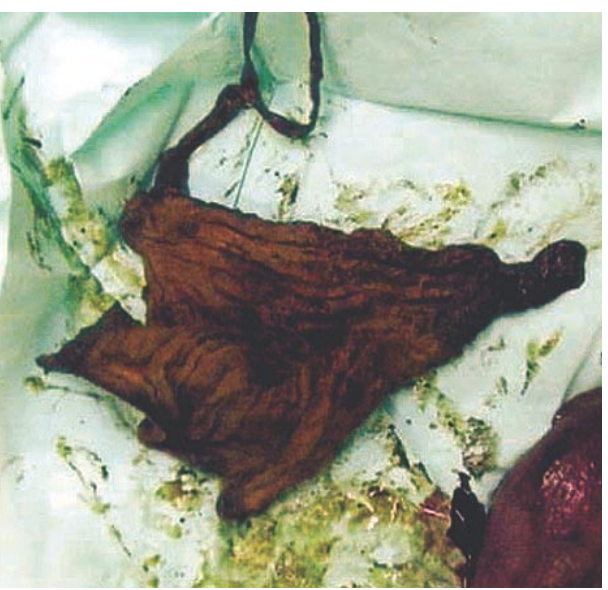

Fig. 6. Laparotomy sponge removed.

\section{Discussion}

The most common surgically retained foreign body is laparotomy sponge ${ }^{[1]}$. The incidence of gossypiboma varies between 1 in 100 and 1 in 3000 procedures $^{[2]}$. Gossypiboma can be discovered within the first 2 weeks ${ }^{[3]}$ or many years later, the longest being 30 years post operatively ${ }^{[4]}$. Its presentation varies from being asymptomatic (found accidentally or may never be discovered) to fatal complications. Clinically, it may present as a palpable mass, low grade fever, acute or chronic abdominal pain, an abscess, intestinal obstruction ${ }^{[5]}$, fistula into any hollow viscus including stomach, duodenum, small bowel, colon, rectum or bladder. $50 \%$ will become symptomatic in the form of erosion into the bowel or vessels, fistulae, abscesses, obstruction, bleeding or chronic pain ${ }^{[6,7]}$. 
Apparently an inflammatory response created an abscess pocket around the sponge between the abdominal wall and the ileum resulting in perforation of the ileum, through the opening the sponge migrated into the lumen of the small bowel, from which it was surgically removed ${ }^{[1,8,9]}$.

Plain X-ray may show a marker if the sponge is labelled with radio-opaque marker or calcification ${ }^{[6,10]}$. A whirl-like pattern has been described as being characteristic of retained sponges ${ }^{[11]}$ this finding may be due to gas of intestinal origin trapped between the fibers of the sponge. CT finding have described foreign body granuloma as round sharply outlined mass with dense enhancing wall. The centre of the lesion have heterogenous densities created by a whirllike structure of high or low attenuation ${ }^{[3,12]}$.

A high index of suspicion is needed to diagnose gossypiboma . Usually it is treated surgically. Laparoscopic retrieval is feasible especially if discovered early ${ }^{[6,13]}$.

Retained surgical sponge is lethal condition when neglected and can lead to major complications when left untreated. All preventive measures should be taken to avoid this condition ${ }^{[14,15]}$. A thorough exploration of all quadrants of the abdomen at the termination of surgical cases is mandatory ${ }^{[1,16]}$. Inspite of all the effort usually done by the nurses in counting the sponge and instrument, the cases of foreign body is still seeing which could be due to failure in the counting by the attending nurses and the responsibility of nursing in missing the foreign body is debatable some consider it the responsibility of surgeon, but in my opinion, is it the surgeon responsibility to clarify that the sponge and instrument count are complete.

Acknowledgment. I would like to thank Professor Yasir S. Jamal for reviewing the manuscript and to Mrs. Joy A. De Silva for her secretarial help.

\section{References}

[1] Dhillon JS, Park A. Transmural migration of a retained laparotomy sponge. Am Surg 2002 68(7): 603-5.

[2] Serra J, Matias-Guiu X, Calabuig R, Garcia P, Sancho FJ, La Calle JP. Surgical gauze pseudotumor. Am J Surg 1988 155(2): 235-237.

[3] Apter S, Hertz M, Rubinstein ZJ, Zissin R. Gossypiboma in the early post-operative period: a diagnostic problem. Clin Radiol 1990 42(2): 128-129.

[4] Rajput A, Loud PA, Gibbs JF, Kraybill WG. Diagnostic challenges in patients with tumors: case 1. Gossypiboma (foreign body) manifesting 30 years after laparotomy. J Clin Oncol 2003 21(19): 3700-3701.

[5] al-Salem AH, Khwaja S. Intestinal obstruction due to retained, eroding surgical sponge. Case report. Acta Chir Scand 1989 155(3): 199-200.

[6] Ibrahim IM. Retained surgical sponge. Surg Endosc 1995 9(6): 709-710. 
[7] Wattanasirichaigoon S. Transmural migration of a retained surgical sponge into the intestinal lumen: an experimental study. J Med Assoc Thai 1996 79(7): 415-422.

[8] Esposito S, Ragozzino A, Rossi G, Pinto A, Martino A. [Spontaneous migration of a surgical sponge in the small intestine. Apropos of a case studied with conventional radiology and CT] Radiol Med (Torino) 1994 88(1-2): 139-41.

[9] Risher WH, McKinnon WM. Foreign body in the gastrointestinal tract: intraluminal migration of laparotomy sponge. South Med J 1991; 84(8): 1042-1045.

[10] Kokubo T, Itai Y, Ohtomo K, Yoshikawa K, Iio M, Atomi Y. Retained surgical sponges: CT and US appearance. Radiology 1987; 165(2): 415-418.

[11] Olnick HM, Weens HS, Rogers JV Jr. Radiological diagnosis of retained surgical sponges. J Am Med Assoc 1955 159(16): 1525-1527.

[12] Zbar AP, Agrawal A, Saeed IT, Utidjian MR. Gossypiboma revisited: a case report and review of the literature. JR Coll Surg Edinb 1998 43(6): 417-418.

[13] Gencosmanoglu R, Inceoglu R. An unusual cause of small bowel obstruction: gossypiboma--case report. BMC Surg 2003; 3(1): 6 .

[14] Ahmad G, Attiq-ur-Rehman S, Anjum MZ. Retained sponge after abdominal surgery. $J$ Coll Physicians Surg Pak 2003 13(11): 640-643.

[15] Silva CS, Caetano MR, Silva EA, Falco L, Murta EF. Complete migration of retained surgical sponge into ileum without sign of open intestinal wall. Arch Gynecol Obstet 2001 265(2): 103-104.

[16] Gupta NM, Chaudhary A, Nanda V, Malik AK, Wig JD. Retained surgical sponge after laparotomy. Unusual presentation. Dis Colon Rectum 1985 28(6): 451-453. 


\title{
حالة مسجلة عن انسداد الأمعاء نتيجة للاحتفاظ بالضماد الجر احي المتآكل
}

\author{
فاطمة خنيفس الثبيتي

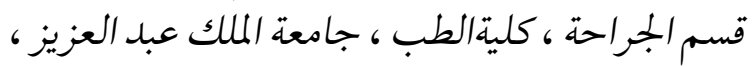

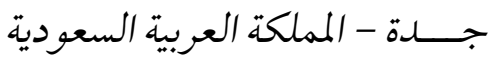

المستخلص . تمت دراسة حالة ترك ضماد من الشاش الطبي المستخدم في الجراحة في التجويف الصفاقي حين إجراء عملية ولادة قيصرية ، وقد

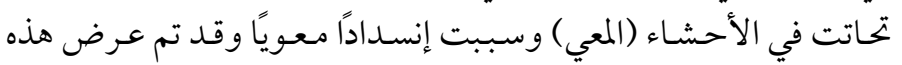

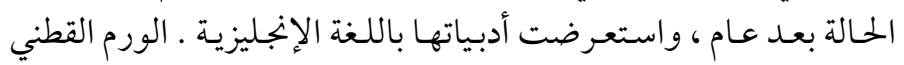

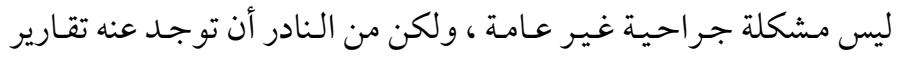
مكتوبة ، وذلك يرجع بصفة أساسية إلى الإشكالات القانونيـة الطبيـة .

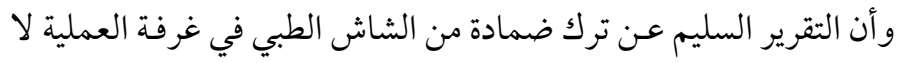

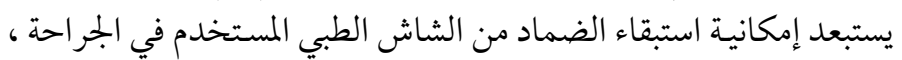

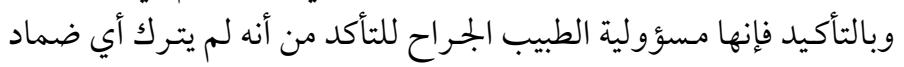

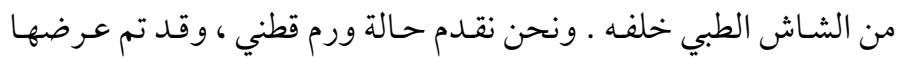

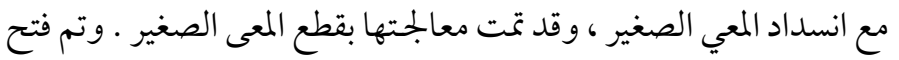
جدار المعي الصغير وإزالة ضماد الشاش الطبي • 